\title{
CONFLITOS ENTRE USOS E PROTEÇÃO DE ESPÉCIES VEGETAIS NAS UNIDADES DE CONSERVAÇÃO DA SERRA DE SÃO JOSÉ, MINAS GERAIS
}

\author{
CONFLICTS BETWEEN USES AND PROTECTION OF VEGETABLE SPECIES IN THE PROTECTED AREAS OF SERRA DE SÃO \\ JOSÉ, MINAS GERAIS
}

\section{RESUMO}

A Área de Proteção Ambiental Serra de São José e o Refúgio Estadual de Vida Silvestre Libélulas da Serra de São José, localizadas na região de Tiradentes-Minas Gerais, apresentam importante diversidade biológica para a conservação, distribuídas em três fitofisionomias: Cerrado, Floresta Estacional Semidecidual e Campos Rupestres. Além de protegerem legalmente o patrimônio natural, abrigam também raizeiros que detêm saberes e práticas sobre o uso de espécies vegetais extraídas nos limites das referidas áreas. Com o objetivo de compreender os conflitos estabelecidos na relação entre a conservação e uso de espécies vegetais, foram realizados levantamentos etnobotânicos por meio de turnês guiadas em três trilhas utilizadas por dois raizeiros, e aplicado questionário semiestruturado, que apontaram as espécies utilizadas, suas aplicações (passado e presente) e as partes empregadas. Concluiu-se, que os conflitos existentes se devem à extração de recursos biológicos na Unidade de Conservação de proteção integral. Todavia, podem contribuir para conservação da biodiversidade das Áreas Protegidas da Serra de São José juntamente com a da etnobotânica e a participação efetiva dos raizeiros.

Palavras-chave: Etnoconservação; Etnobotânica; Áreas Protegidas; Conhecimento tradicional; Políticas públicas.

\begin{abstract}
Protection Area Serra de São José and the State Refuge of Wildlife Libélulas of Serra de São José, located in the region of Tiradentes-Minas Gerais present important biological diversity for conservation distributed in three phytophysiognomies: Cerrado, Semideciduous Seasonal Forest and Rupestres Fields. In addition to legally protecting the natural heritage, they also shelter "raizeiros" that have knowledge and practices about the use of plant species extracted within the limits of the mentioned areas. Aiming to understand the conflicts established in the relationship between the conservation and the use of plant species, ethnobotanical surveys were conducted through guided tours in three tracks used by the two "raizeiros", and a semistructured questionnaire was used in order to indicated the species used both in past and presente, and also the employed parts. It was concluded that the existing conflicts are due to the extraction of biological resources in the Conservation Unit of integral protection. However, they can contribute to the conservation of the biodiversity of the Serra de São José Protected Areas concomitantly with the ethnobotany one, and the effective participation of the "raizeiros".
\end{abstract}

Keywords: Ethnoconservation; Ethnobotany; Protected Areas; Traditional knowledge; Public politics.

(D) Wanderley Jorge da Silveira
Junior a
(D) Cléber Rodrigo de Souza a
(D) José Emílio Zanzirolani de
Oliveira ${ }^{\text {b }}$
(D) Aloysio Souza Moura a
(D) Marco Aurélio Leite Fontes ${ }^{\text {a }}$
a Universidade Federal de Lavras (UFLA),
Lavras, MG, Brasil
b Instituto Federal do Sudeste de Minas
Gerais (IFSUDESTEMG), Barbacena, MG,
Brasil
Dol: $10.12957 / g e o u e r j .2020 .37383$
Correpondência: jjjuniorjf@hotmail.com
Recebido em: 19 set. 2018
Revisado em: 6 out. 2020
Aceito em: 9 out.2020




\section{INTRODUÇÃO}

O estabelecimento de Áreas Protegidas (AP) se tornou a principal estratégia, para a conservação da natureza, com consequências positivas, na manutenção dos recursos hídricos, segurança alimentar (PITTOCK et al., 2015; DUDLEY et al, 2017), turismo (LEUNGE et al., 2015), e na economia de vilas, cidades, regiões e países (OVETZ, 2006; STOLTON et al., 2015). No entanto, a criação de AP baseada no modelo "fortress conservation" (BROCKINGTON et al., 2006) resultou em uma série de conflitos e impactos para as populações humanas que habitavam estas áreas, pois, ou foram expulsas ou reassentadas em outros locais (BROCKINGTON; SCHMIDT-SOLTAU, 2004; PRETTY; SMITH, 2004; ADAMS; HUTTON, 2007; MCSHANE et al., 2011).

O modelo ainda hoje é considerado o principal fator causador de conflitos socioambientais denominados "parks vs. people" (DE POURC et al., 2015; DE POURC et al., 2017; BROCKINGTON; SCHMIDTSOLTAU, 2004; BROCKINGTON et al., 2006), contribuindo para o empobrecimento das populações autóctones (SCHERL et al., 2006), impulsionados sobretudo pelos impactos negativos das medidas de conservacionistas que restringem o uso direto dos recursos naturais (ADAMS et al., 2004; BROCKINGTON et al., 2006; VEDELD et al., 2012; DE POURCQ et al. 2017).

Os conflitos que ocorrem na conservação são constantemente confundidos com impactos, quando na verdade tem sua origem neles (YOUNG et al., 2010). Podem ser caracterizados quando os atores sociais percebem os prejuízos (impairments) em consequência dos impactos causados pelas ações de outros atores sociais (DE POURCQ et al., 2017). No entanto, não existe unanimidade sobre o papel dos conflitos na sociedade, que reflete numa divergência entre duas perspectivas científicas. Na primeira, é considerado como inerente aos processos sociais, nos quais não há resolução definitiva, todavia, é capaz de produzir mudanças. Na segunda, são apontados como negativos, e precisam ser neutralizados (VAYRYNEN, 1991; FERREIRA, 2005). A primeira perspectiva compreende os conflitos como componente integral e positivo da conservação da biodiversidade, como oportunidade de construir confiança entre os envolvidos, ou seja, o reconhecimento da existência dos conflitos e a busca pela sua resolução de forma coletiva pelas partes interessadas (YOUNG et al 2010; YOUNG et al., 2016; SILVEIRA-JUNIOR et al., 2020).

A Serra de São José, em Minas Gerais, abriga duas Unidades de Conservação (UC), a Área de Proteção Ambiental da Serra São José e o Refúgio Estadual de Vida Silvestre Libélulas da Serra de São José, que além de protegerem a diversidade de espécies vegetais ali presentes, possibilitam também seu uso, por meio da prática tradicional realizada por raizeiros locais.

Desta forma, este estudo fundamenta-se na hipótese que existe conhecimento tradicional e uso de espécies vegetais nas Áreas Protegidas (AP) Brasileiras. No entanto, o uso destes recursos biológicos gera conflitos entre os órgãos ambientais gestores das áreas, e as populações extrativistas, sobretudo quando estas são de proteção integral (PI) (categorias la, lb, II, e III da IUCN). Nesta direção, algumas questões surgiram e nortearam este estudo: Existem conflitos socioambientais entre os extrativistas detentores de conhecimento 
tradicional e o órgão gestor das UC relacionados a extração de espécies vegetais nas AP da Serra de São José? De que forma estes conflitos podem contribuir para a conservação das AP?

A partir das questões levantadas, este estudo objetivou analisar os usos passados e presentes de espécies vegetais extraídas na Área de Proteção Ambiental da Serra São José e no Refúgio Estadual de Vida Silvestre Libélulas da Serra de São José, em Minas Gerais, analisando os conflitos existentes, bem como os saberes e práticas empregados na atividade extrativista e na conservação das espécies vegetais.

A realização desta pesquisa se justificou devido à necessidade de se registrar os possíveis conhecimentos tradicionais sobre as espécies vegetais existentes dentro das UC, e compreender o papel dos conflitos estabelecidos pelas politicas públicas de comando e controle. Outro fator importante e que justificou a realização deste estudo, está no fato de inexistir pesquisas publicadas neste campo disciplinar sobre a Serra de São José. Desta forma, os resultados começariam a preencher esta lacuna.

\section{METODOLOGIA}

\section{Caracterização da área de estudo}

A área estudada está inserida na região do Campo das Vertentes, Minas Gerais, e abrange os municípios de Coronel Xavier Chaves, Prados, Santa Cruz de Minas, São João del-Rei e Tiradentes (Fig 1).

Figura 1. localização das UC da Serra de São José em Minas Gerais e municípios abrangidos

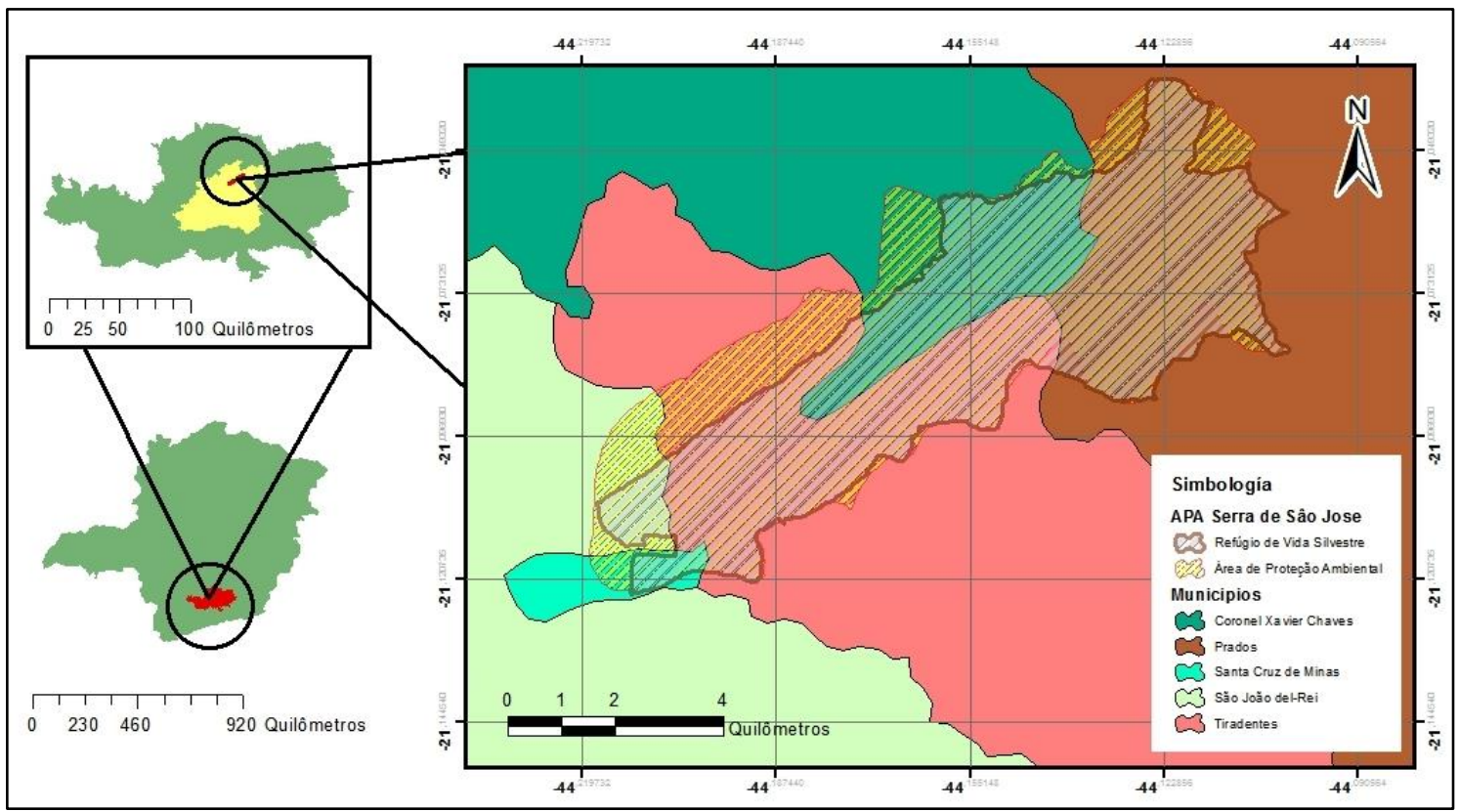

A serra é constituída por formações vegetais da Floresta Atlântica (Floresta Estacional Semidecidual), possuindo um dos maiores fragmentos dessa tipologia na mesorregião, além de campos rupestres e formações savânicas (Cerrado) (FABRANDT, 2000). 
A região objeto desse estudo tem grande importância para a conservação, mas em diferentes níveis para os grupos de táxons, a saber: muito alta para invertebrados, alta para répteis e anfíbios e extrema para flora e aves (DRUMMOND et al., 2005). Sua relevância para conservação justifica a existência de duas UC que abrangem toda serra. Primeiro foi criada Área de Proteção Ambiental-APA da Serra São José, que tem como objetivos a proteção e preservação dos mananciais, da cobertura vegetal (Cerrado e remanescentes de Mata Atlântica) e da fauna silvestre, e também a preservação do patrimônio histórico, paisagístico e cultural da região (MINAS GERAIS, 1990); o Refúgio Estadual da Vida Silvestre-REVIS Libélulas da Serra de São José, foi criado sobrepondo a APA, com o objetivo principal de assegurar a conservação da biodiversidade regional, com ênfase na fauna de Odonatas (libélulas) (MINAS GERAIS, 2004).

O projeto dessa pesquisa foi submetido à aprovação prévia do Comitê de Ética Pública da Universidade Federal de Lavras, que o considerou em conformidade com todos os requisitos de acordo com o parecer 1.126.959 em 26/06/2015. A coleta de dados foi realizada em cinco visitas periódicas à Serra do São José, entre os meses de março e junho de 2015. Para responder as questões que nortearam este estudo, realizamos levantamento etnobotânico por meio de métodos e técnicas utilizados em pesquisas etnobiológicas e etnoecológicas como, observação participante e entrevistas (SIEBER et al., 2014), que se desenvolveu em duas etapas. Na primeira, visitamos o entorno das áreas protegidas (AP) a fim de identificar especialistas locais sobre o conhecimento e uso de espécies vegetais. Para isso, investigamos 50 moradores dos cinco municípios abrangidos pelas AP, residentes no entorno imediato das áreas, apresentando os objetivos do estudo e indagando sobre possíveis conhecedores sobre o uso e espécies vegetais na região.

A segunda etapa da coleta de dados consistiu na realização de turnês guiadas com especialistas locais (ALBUQUERQUE et al., 2014), identificados na primeira etapa, com o intuito de verificar nas áreas das UC as espécies utilizadas. Nesta etapa, os especialistas foram entrevistados por meio de um questionário semiestruturado (SILVA et al., 2014), no qual, primeiramente, buscou-se informações sobre as espécies apontadas por eles. As respostas foram registradas em um formulário numerado com data da coleta, número do raizeiro e da turnê. Os raizeiros forneceram o nome popular, os tipos de usos sobre as espécies (Medicinal, Ornamentação, Utilização Doméstica, Construção, Combustível, Religiosa e Alimentação), tempo de uso, e se ainda são ou não utilizadas (passado ou presente). Para verificarmos os conhecimentos que os raizeiros tem sobre as espécies, e o manejo realizado sobre elas, e os conflitos existentes, gravamos as entrevistas realizadas ao longo dos percursos, orientadas pelas questões do questionário, que interrogavam sobre, a existência de conflitos, época e forma de extrair, se o uso sustentável é uma preocupação, e a origem e a transmissão dos conhecimentos sobre as espécies. Utilizamos ainda, notas e diário de campo para registrar observações e informações relevantes para análise dos dados (MACEDO, 2006; ALBUQUERQUE et al., 2014).

As plantas coletadas foram herborizadas conforme as técnicas apontadas em Santos et al. (2014), e as exsicatas enviadas para identificação à especialistas do Laboratório de Ecologia Florestal da Universidade 
Federal de Lavras, e ao Laboratório de Biologia do Instituto Federal de Educação, Ciência e Tecnologia do Sudeste de Minas Gerais, campus Barbacena.

Com o intuito de verificarmos se as espécies eram extraídas fora ou dentro das UC e, em qual tipologia, fizemos o registro da localização geográfica onde as mesmas são extraídas, por meio de aparelho GPS (Global Positioning System) durante os percursos das turnês guiadas. Para facilitar a identificação das espécies extraídas, realizamos o registro fotográfico das espécies em sua área de ocorrência utilizando máquina fotográfica digital.

\section{RESULTADOS}

\section{Levantamento etnobotânico}

O resultado do levantamento etnobotânico apontou que o Raizeiro-1, em duas turnês guiadas e o Raizeiro-2 em sua única turnê, detêm conhecimento sobre 63 espécies, indicando 81 tipos de usos (figura 2). Deste total, 84\% (68) ainda são praticados, enquanto que 16 \% (13) não são mais realizados, como é o caso do uso de arbóreas para construção e reforma das casas ou mourão em cercas com cinco indicações, para combustível em fogão a lenha com duas, e herbáceas, com três para utilidade doméstica, duas para fins religiosos e uma de emprego na ornamentação de casas e igrejas.

Figura 2. Localização das três turnês guiadas e espécies utilizadas pelos raizeiros, em suas áreas de ocorrência, dentro e fora das UC da Serra de São José.

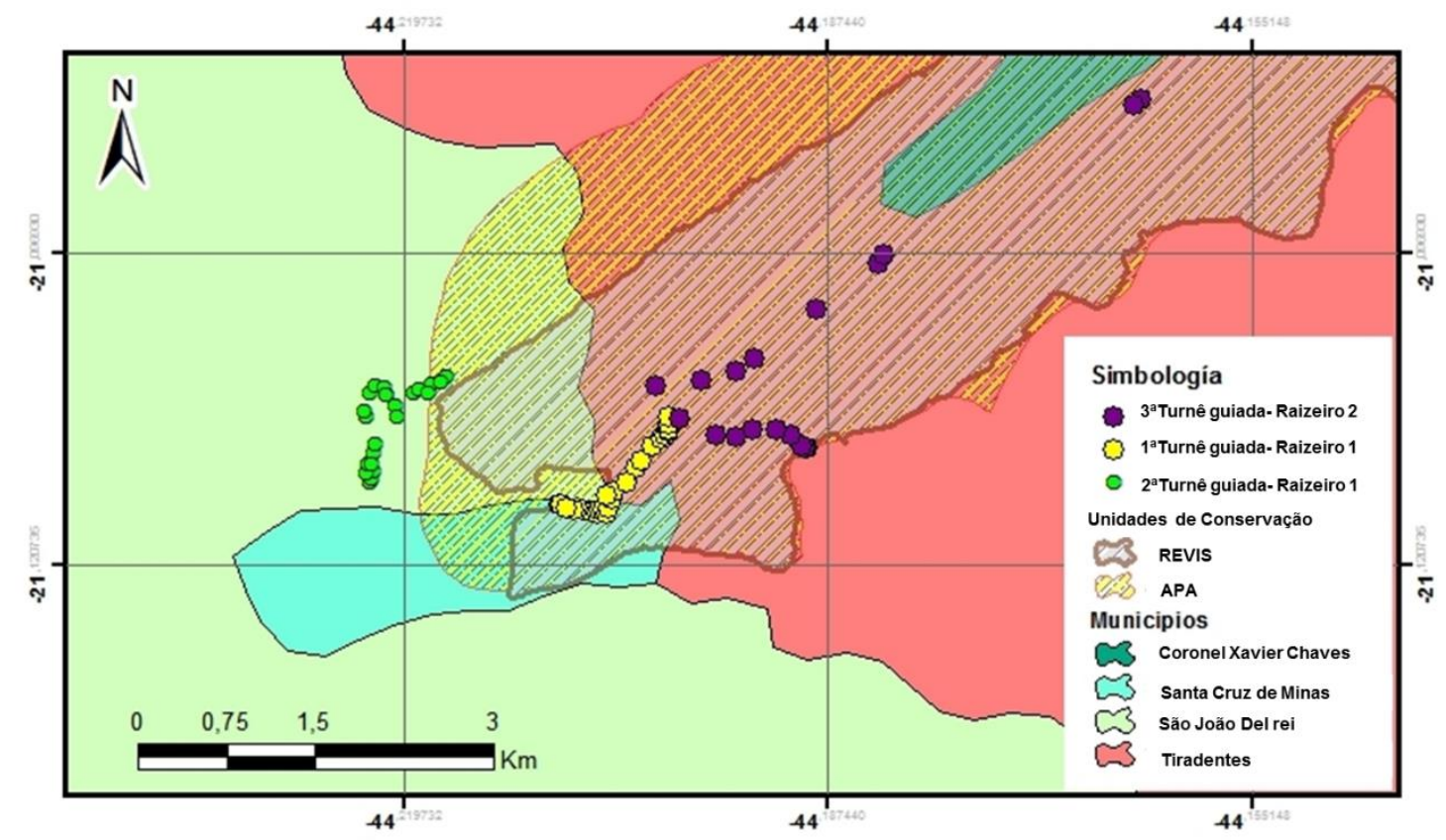

Conforme observado na figura-3, do total que ainda é extraído e utilizado, as aplicações fitoterápicas continuam sendo amplamente utilizadas em detrimento de outras formas de uso abandonadas ou realizadas em menor escala. Além dos conhecimentos sobre as espécies vegetais, foram identificados também neste 
estudo alguns cuidados na extração e manejo, demonstrando preocupação dos extrativistas com a perpetuidade das mesmas, que se revela nas estratégias de dispersão, nos cuidados na extração e no manejo em suas residências. Ambos raizeiros revelaram a estratégia de trazer sementes e plântulas que estão localizadas em áreas mais distantes com o intuito de semear ou plantar mais próximo de suas casas, observando e respeitando as características abióticas da área de origem, como a textura, umidade e cor solo; e disponibilidade de luz. Dispersar as espécies facilita a extração por meio de incursões mais rápidas e próximas a sua residência, diminuindo o tempo nas trilhas e aumentando a população das mesmas. A saber: Costus spicatus (cana-do-brejo), Echinodorus macrophillus (chapéu-de-couro) e Cymbopogon martinii (capim São José).

Durante o manejo das espécies em sua residência, as sementes que sobram nos processos de separação, desidratação e empacotamento, são espalhadas nas áreas onde foram extraídas. Em relação aos cuidados na coleta, ambos extrativistas relataram saberes e práticas objetivando a perenidade das espécies. Retiram cascas, folhas e sementes sem danificar as estruturas das espécies arbóreas, respeitando seu desenvolvimento e sua dispersão. Na extração dos cipós observam quais guias devem ser cortadas e em que parte, buscando evitar a destruição das mais novas e em formação e o aumento de guias na rebrota.

Figura 3. Usos de espécies vegetais ainda praticados dentro das UC da Serra de São José. As categorias se diferenciam significativamente pelo teste chi-quadrado ao nível de $5 \%$ de significância

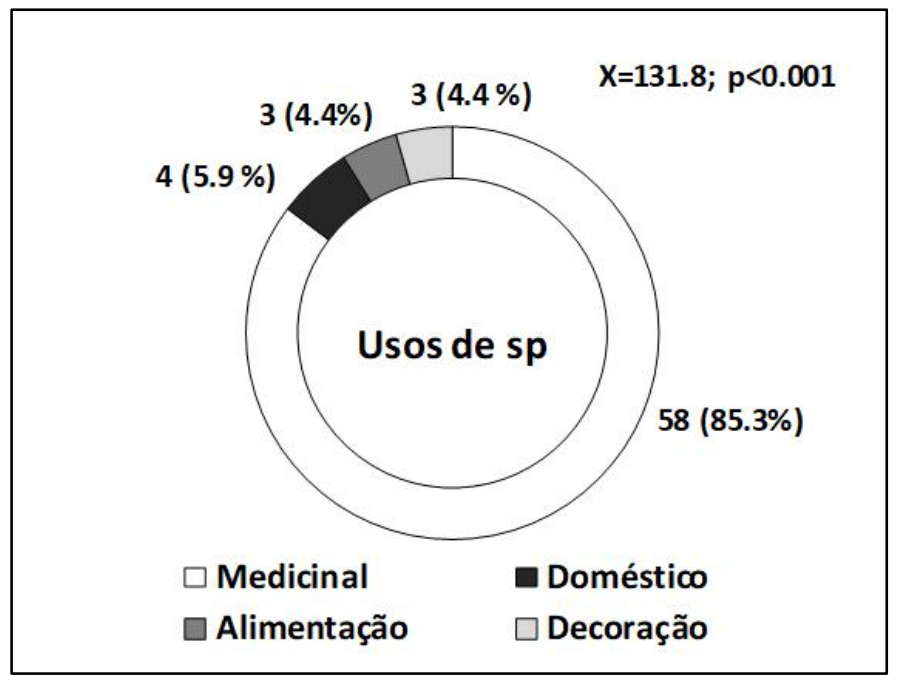

Um fato que merece ser destacado é a dificuldade de encontrar determinadas plantas, sobretudo aquelas na qual a raiz é a principal parte utilizada, como a Chioccocca alba (raiz preta ou cainca) e a Remijia ferrugínea (quina barroca). Esta segunda, conforme revelou o Raizeiro-1, e constatado na turnê Guiada-1, é necessário cada vez sair das trilhas, pois é difícil achá-la em áreas em que antes era abundante. Questionado sobre a possível causa, apontou a coleta excessiva e feita de forma incorreta por pessoas que não detêm o conhecimento e não se preocupam com os impactos provocados pelo uso indiscriminado. 
Segundo o Raizeiro-1, um fato que representa preocupação é a ausência de algumas espécies que antes eram encontradas facilmente nas trilhas percorridas, a saber: ${ }^{1 “ j o a ̃ o-b o l a ̃ o ”, ~ " j o a ̃ o-d a-C o s t a ”, ~ “ c a j u-d o-~}$ Campo", "porungaba", "velame ou jurubeba-de-cupim", "paratudo" e "douradinha".

\section{Conflitos entre a conservação e o uso de espécies vegetais}

Apenas uma pequena parte das espécies vegetais é extraída dentro da APA da Serra de são José, ou fora das duas AP. Como pode ser observado na figura 4, a extração é feita quase que em sua totalidade dentro da mais restritiva, o REVIS Libélulas da Serra de São José, e que devido as restrições preconizadas na Lei 9.985/2000, impossibilitam o extrativismo dentro dos seus limites. A proibição de extração dentro da APA e fora dos limites das áreas protegidas é estendida a algumas espécies listadas na deliberação do Conselho de Política Ambiental do Estado de Minas Gerais (COPAM) no 367, de 15 de dezembro de 2008, por estarem ameaçadas de extinção no estado de Minas Gerais.

Figura 4. Quantidade e porcentagem de espécies extraídas dentro e fora dos limites das UC da Serra de São José. As categorias se diferenciam significativamente pelo teste chi-quadrado ao nível de $5 \%$ de significância.

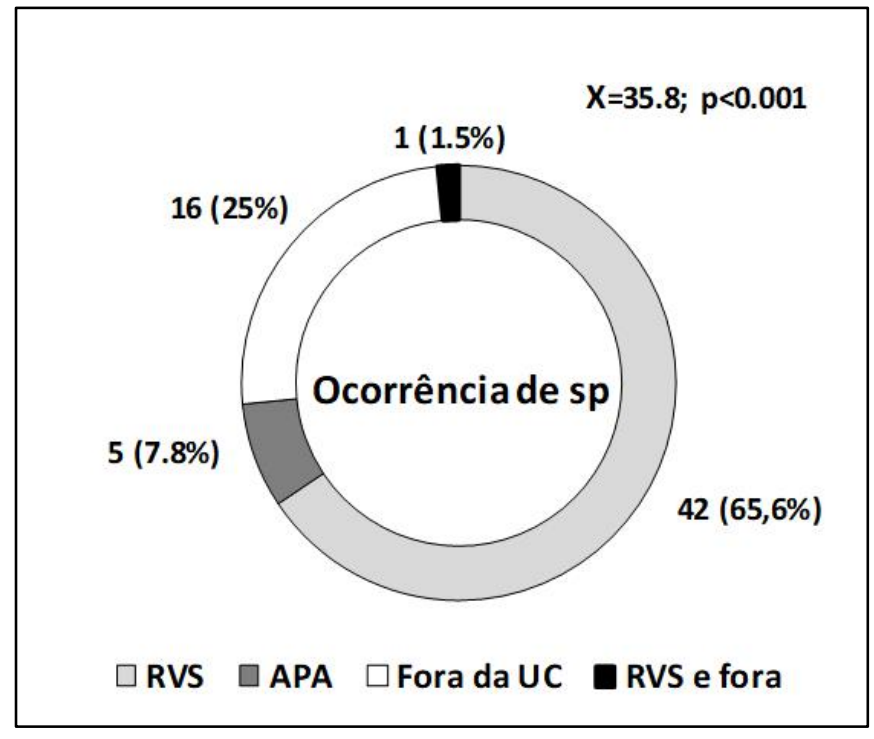

Para o Raizeiro-2 a criação do REVIS impossibilitou o uso de madeira, sobretudo da Eremanthus erythropappus (candeia-branca), que era muito utilizada para cercar os terrenos e como combustível para fogão a lenha. Conforme relatado pelo Raizeiro-1, na área do REVIS existe fiscalização, e a proibição de extrair não se detêm apenas as espécies arbóreas, mas também as herbáceas como as Achyrocline alata, $A$. satureoides (macelas amarelas) e A. albicans (macela branca), coletadas pelos raizeiros anualmente para comercialização.

\footnotetext{
${ }^{1}$ Como estas espécies não foram encontradas, e, portanto, não houve identificação, utilizou-se apenas o nome popular.
} 
Por outro lado, no entendimento do Raizeiro-2 não existe proibição de extrair plantas medicinais, nem mesmo dentro do REVIS, pois segundo ele, quando há coleta, são extraídas pequenas quantidades, somente o que lhe é encomendado por terceiros. O conflito reside mais na extração de material lenhoso utilizado na construção e reparo das casas e na coleta da espécie Lychnophora passerina (Mart. ex DC.) Gardner (arnicada-serra), que é utilizada na medicinal tradicional, mas devido à grande exploração no passado na região, sobretudo em comemorações e ritos religiosos, teve sua extração vetada. A referida espécie só ocorre na serra nas áreas de campos rupestres que estão restritas aos limites do REVIS.

\section{DISCUSSÃO}

Mesmo diante da perceptível evolução da construção da conservação da natureza no mundo, diversos conflitos ainda ocorrem. Mesmo no Brasil, onde o processo de conservação da natureza sempre buscou conciliar o uso e conservação de acordo as especificidades de cada caso (MEDEIROS et al., 2006). Desta forma, pode-se entender que os conflitos, inerentes à vida em sociedade (SIMMEL, 1986), também existem na criação e gestão de áreas protegidas (YOUNG et al., 2016) , pois sempre haverá interesses opostos envolvendo a população local que faz uso dos recursos biológicos e os órgãos ambientais que buscam cumprir a legislação pertinente às Unidades de Conservação (DE POURCQ et al., 2015; 2017). Como foi constatado, as UC da Serra de São José ainda abrigam raizeiros que detêm um grande conhecimento sobre as espécies vegetais e suas aplicações, que se estendem também para forma de coletar. Saberes sobre as características da área de extração, como umidade e tipo do solo e práticas que contribuem para perenidade das mesmas.

Neste sentido, e de acordo com os conceitos BERKES, 2004; ALBUQUERQUE; FERREIRA JUNIOR, 2016) pode-se afirmar que se trata de Conhecimento Ecológico Tradicional (CET), resultado do processo de evolução cultural por processos adaptativos de grupos sociais em interação com a natureza, e que se refletem na alimentação, construção e moradia. Todavia, o desuso das espécies vegetais em quaisquer destas práticas, seja por substituição por outras fontes ou formas de serem obtidas, ou ainda por restrição de uso, pode levar à perda de conhecimento sobre referidos usos, podendo até mesmo conduzir à adoção de práticas extrativistas não tradicionais e, por vezes, mais impactantes (DIEGUES, 2001).

Ou seja, o desuso de espécies vegetais, no caso deste estudo as arbóreas utilizadas na construção ou como combustível, podem estar provocando a perda de conhecimentos referentes aos seus usos. Neste caso, a legislação aplicada às UC, especificamente o decreto de criação do REVIS Libélulas da Serra de São José, vem impossibilitando a continuidade da atividade. No caso da espécie Lychnophora passerina (Mart. ex DC.) Gardner (arnica-da-serra), usada nos ritos religiosos, a restrição está relacionada diretamente à sua presença no anexo I da Deliberação COPAM no 367/2008, na qual seu grau de ameaça é vulnerável, ou seja, táxon que corre um risco alto de extinção na natureza em médio prazo.

Como pôde ser constatado, prevaleceu o uso medicinal em comparação às demais formas de uso presente. A decisão do gestor das UC de não proibir a extração plantas medicinais em pequenas quantidades 
dentro das UC pode ter contribuído para manutenção das práticas tradicionais, e consequentemente para este resultado. No entanto, estudos de Coe e Anderson (1997) na Nicarágua, Chazdon e Coe (1999) na Costa Rica, Camejo-Rodrigues et al. (2003) em Portugal, Toledo et al., (2003) no México e Hanazaki (2003) na Mata Atlântica brasileira, também apresentam as indicações de uso de espécies vegetais para fins medicinais em maior numero que as outras indicações, mostrando assim, ser padrão nos resultados de levantamentos etnobotânicos.

Todavia, existe consenso entre os raizeiros que o uso de plantas medicinais está diminuindo na Serra de São José em detrimento ao uso de medicamentos alopáticos. Segundo os mesmos, este fato aliado à falta de interesse dos mais jovens em aprender sobre as trilhas da Serra, as espécies vegetais existentes e seus usos, está favorecendo o desuso e a consequente perda do conhecimento. Neste sentido, as mudanças culturais também estão influenciando a perda de conhecimento tradicional. Conforme Mesouldi (2011), a cultura em seu processo evolutivo está sujeita a diversas influências, que variam no espaço e no tempo.

Em concordância com os resultados das pesquisas de Medeiros et al. (2006) sobre UC no Brasil, os conflitos relacionados às UC da Serra de São José surgiram devido a inexistência de estratégias do poder público estadual em integrar as UC às dinâmicas locais, neste caso a conservação ao uso dos recursos biológicos, pois a criação do REVIS sobrepondo cerca de 75\% a área da APA, se justifica pela importância da área para conservação. Todavia a categoria de PI escolhida diminuiu drasticamente o espaço para o uso sustentável. O fator agravante que pode ser constatado no documento de Fabrandt (2000), é que os 25\% restantes destinados a APA e ao uso sustentável, abrigam a produção agrícola de Coronel Xavier Chaves, a mineração em São João Del Rei e a expansão urbana em Santa Cruz de Minas, São João Del Rei, Tiradentes e Prados, ou seja, dentro dos limites da APA praticamente não há extrativismo, pois outras atividades já transformaram a paisagem. Portanto, o extrativismo somente é realizado onde os recursos biológicos ainda estão conservados, ou seja, nos limites do REVIS.

Pode-se compreender os conflitos socioambientais na perspectiva de Acserald (2004), para quem ocorrem quando grupos sociais tentam impor a outros sua forma de apropriar e de se relacionar com o meio ambiente. Nesta perspectiva, na Serra de São José eles existem devido a posições divergentes de apropriação, de um lado o poder público representado pelo órgão ambiental, Instituto Estadual de Florestas (IEF), e do outro os raizeiros. Os primeiros objetivam a conservação da natureza cumprindo a legislação aplicada às UC no Brasil, enquanto o segundo busca a manutenção das suas atividades tradicionais extrativistas.

Como a criação da primeira UC na Serra de São José data da década de 1990, com a criação da APA, e o uso de espécies vegetais já era praticado pelos pais e avôs dos raizeiros, é correto afirmar que o ideário conservacionista se sobrepôs às atividades extrativistas. No entanto, os raizeiros afirmam que criação da APA não trouxe restrições quanto ao uso de espécies vegetais, corroborando assim com as considerações de Cabral e Souza (2005), quando afirmam que a baixa ocorrência de conflitos socioambientais nesta tipologia de UC é um ponto positivo, demonstrando assim que poucas restrições de uso geram menos conflitos. 
A criação da APA também reafirma que o modelo conservacionista brasileiro não se resumiu a uma cópia do modelo estadunidense de Wilderness, pois sempre buscou-se adequar as realidades regionais, conforme colocado por Medeiros et al. (2006). Por outro lado, as poucas restrições de uso dos recursos naturais existentes nesta tipologia é um ponto negativo quando o objetivo é a conservação da biodiversidade, assim como afirmou Pádua (2001), sobretudo se considerarmos a importância biológica da Serra de São José na conservação da biodiversidade, como demonstrado pelos resultados de Drummond et al. (2005), os quais demonstram a relevância da área para a conservação de invertebrados, aves, répteis, anfíbios e da flora. Neste sentido, parece justificável a criação do REVIS sobrepondo os limites da APA em quase $75 \%$ dos seus 5000 ha. Por outro lado, a efetivação da referida UC de proteção integral favoreceu o desenvolvimento de conflitos socioambientais.

De acordo com Ferreira (2005), pode-se compreender os conflitos estabelecidos nas UC da Serra de São José de duas formas: (a) a extração de espécies vegetais é problema, pois gera conflitos, causa problemas no processo conservacionista considerado ideal, sendo a proibição da extração a forma de acabar com o conflito. No entanto, o fim da prática extrativista, conforme Diegues (2011), pode contribuir com a perda de conhecimento tradicional. Perde-se ainda a oportunidade de realizar estudos etnobotânicos que, segundo Albuquerque (2002), podem contribuir para conservação da biodiversidade, descobrir novos cultivares e suas propriedades medicinais, e contribuir com a documentação do conhecimento tradicional e sistemas de manejo e conservação dos recursos naturais. Na segunda forma, na perspectiva de Ferreira (2005), os conflitos estabelecidos são inerentes ao contexto social e podem provocar mudanças positivas, assim como colaborar com a conservação da diversidade biológica, aproximando os órgãos ambientais e os extrativistas.

Apoiando-se na segunda compreensão, na perspectiva de Young et al. (2010) e Young et al., 2016), os conflitos suscitados na pesquisa se apresentam como oportunidade para o aprimoramento da conservação das UC em questão, por meio da aproximação e estabelecimento da confiança entre raizeiros e órgão ambiental. Para Silveira-Junior et al. (2020), ao ser evidenciado, o conflito possibilita o estabelecimento de acordos e arranjos legais entre o poder público e os raizeiros, que vai beneficiar principalmente os objetivos das UC. Também numa perspectiva positiva, os conflitos podem colaborar construindo um caminho único, conforme considerações de Simmel (1986), favorecendo a criação de políticas ambientais que corroborem com as diretrizes da Convenção da Diversidade Biológica, realizada na 2a Conferência das Nações Unidas para o Meio Ambiente e Desenvolvimento em 1992, na qual ficou estabelecido que os conhecimentos tradicionais deveriam ser protegidos e o uso dos recursos biológicos deveriam ser encorajados, desde que compatíveis com conservação ou utilização sustentável (MMA, 2000).

Nesta direção, Albuquerque (2002) aponta que os estudos etnobotânicos podem contribuir na criação de programas de desenvolvimento e preservação dos recursos naturais dos ecossistemas, além de auxiliar na mitigação de danos às espécies extraídas. No caso específico da Serra de São José, as mais extraídas, aquelas não encontradas ou com poucos indivíduos durantes as turnês Guiadas. 
A Lei 9.985/2000 estabeleceu instrumentos importantes que favorecem a criação e gestão de UC com participação e justiça social, como os estudos prévios destinados a inventariar os meios biótico, abiótico e antrópico, as consultas públicas que antecedem a criação das UC e os conselhos gestores. Os conselhos gestores regulamentados pelo Decreto no 4.340/2002, tem entre suas finalidades, buscar a compatibilização dos interesses dos diversos segmentos sociais relacionados com a UC e ainda propor diretrizes e ações que permitam compatibilizar, integrar e otimizar a relação com a população do entorno ou do interior da unidade.

Desta forma, pode-se afirmar que a possibilidade de atenuar os conflitos ambientais buscando posição única, integrando os interesses dos extrativistas e os do poder público a favor da conservação da biodiversidade na Serra de São José é responsabilidade e também oportunidade do conselho gestor, que pode, a partir das suas atribuições, incentivar e intermediar o diálogo do representante do Instituto Estadual de Florestas com os extrativistas, com o intuito de viabilizar o uso de espécies vegetais com a conservação da biodiversidade. Um fator importante, é que o gestor das unidades de conservação da Serra de São José não sinaliza negativamente ao extrativismo na Área de Proteção Ambiental (APA) da Serra de São José, onde o uso direto dos recursos naturais pode ser legalmente permitido ou quando este ocorre no Refugio Estadual da Vida Silvestre (REVIS) e se destina à extração para uso próprio e se trata de pequenas quantidades.

Todavia, a compatibilização dos objetivos não é tão simples, pois ambos os raizeiros relacionados neste estudo tem objetivos divergentes aos da legislação aplicada. Para o Raizeiro-1 o produto da extração de espécies vegetais para fins medicinais é destinado ao uso comercial, o que demanda a retirada de grandes quantidades. O Raizeiro-2, que extrai pequenas quantidades também para uso medicinal, busca ocasionalmente a retirada de grandes quantidades de determinadas espécies para usos religiosos, como Hyptis carpinifolia (rosmaninho) e Lychnophora passerina (Mart. ex DC.) Gardner (arnica-da-serra).

O fator agravante é que a maioria do extrativismo ocorre no REVIS, unidade na qual a atividade não é prevista na Lei 9.985/2000. Sendo assim, três alternativas surgem como possibilidade para amenizar os conflitos. A primeira seria redefinir os limites do REVIS, retirando as áreas utilizadas pelos extrativistas da unidade de proteção integral para inclui-las na Área de Proteção Ambiental (APA), na qual o extrativismo pode ser permitido. Nesta opção, existe o risco das novas áreas inclusas serem pressionadas e impactadas como as demais áreas da APA, e assim, tanto a conservação da biodiversidade quanto os conhecimentos tradicionais estariam ameaçados.

A segunda alternativa seria consentir e incentivar a extração somente dentro dos limites da APA, por meio de programas de extração sustentável. Todavia, considerando a quantidade de espécies extraídas na APA, esta alternativa reduziria drasticamente as opções de uso pelos raizeiros, o que não contribuiria para amenizar os conflitos, mas sim para aumentar.

Considerando o baixo impacto da atividade extrativista na serra, justificado pelo reduzido numero de raizeiros e pelos fins que estes buscam, a terceira seria a efetivação de uma Termo de Compromisso (TC) entre os raizeiros e o órgão gestor das Unidades, o Instituto Estadual de Florestas (IEF), baseado na Instrução 
Normativa do Ministério de Meio Ambiente e do Instituto Chico Mendes de Conservação da Biodiversidade no 26, de 4 de JULHO de 2012, a qual favoreceria a extração dentro do REVIS. Neste caso, a efetivação do TC seria apoiada em levantamentos etnobotânicos, que permitiriam conhecer a distribuição, população, ecologia e a importância social das espécies utilizadas pelos extrativistas na APA.

\section{CONCLUSÃO}

Norteado na hipótese do presente trabalho, conclui-se que restrições impostas pela legislação que impedem extração de espécies vegetais nos limites do REVIS Libélulas da Serra de São José, contribuem para a existência de conflitos ambientais e para perda de conhecimento tradicional. Foi constado que a extração em excesso de plantas medicinais, com objetivos comerciais e para ornamentação de eventos religiosos, é um dos principais fatores motivadores. Constatou-se ainda que a perda do saber tradicional é motivada também pelas mudanças culturais, identificada no uso de tratamento com medicamentos alopáticos em detrimento do uso plantas medicinais. Conclui-se que conflitos suscitados neste estudo estão colaborando na construção de um caminho único, que favoreça a criação de políticas ambientais alternativas, integradoras da conservação da biodiversidade e do desenvolvimento local, que protejam e agreguem os conhecimentos tradicionais, no qual a etnobotânica pode contribuir na criação de projetos de desenvolvimento e preservação dos recursos naturais dos ecossistemas presentes nas unidades de conservação da Serra de São José, auxiliando na mitigação de danos às espécies extraídas, com ênfase sobre as que apresentam grande demanda de uso.

\section{REFERÊNCIAS}

ALBUQUERQUE, U. P. Introdução à Etnobotânica. Recife: Bagaço, 2002.

ALbuqUerque, U. P.; Methods and Techniques Used to Collect Ethnobiological Data: in ALBUQUERQUE U. P. et al. Methods and Techniques in Ethnobiology and Ethnoecology. Springer New York Heidelberg Dordrecht London, 2014.

ALBUQUERQUE, U. P.; FERREIRA JUNIOR W. S. What Do We Study in Evolutionary Ethnobiology? Defining the Theoretical Basis for a Research Program. Evol Biol, 2016.

ACSERALD, H. Conflitos ambientais- a atualidade do objeto. In: ACSERALD, H. Conflitos Ambientais no Brasil. Rio de Janeiro: Relume Dumará: Fundação Heinrich Böll, p.1-12, 2004.

ADAMS, W. M.; AVELING, R.; BROCKINGTON, D.; DICKSON, B.; ELLIOTT, J.; HUTTON, J.; ROE, D.; VIRA, B.; WOLMER, W. Biodiversity Conservation and the Eradication of Poverty. Science, v. 306, n. 5699, p. 1146-1149, 2004.

ADAMS, W.; M.; HUTTON, J. People, parks and poverty: political ecology and biodiversity conservation. Conservation and society, v. 5, n. 2, p. 147-183, 2007.

BERKES, F. Repensando Baseado na comunidade Conservação. Conservation Biology. V. 18, n. 3, 2004.

BRASIL. Lei no 9985/00 de 18 de julho de 2000. Regulamenta o art. 225, § 1o, incisos I, II, III e VII da Constituição Federal, institui o Sistema Nacional de Unidades de Conservação da Natureza e dá outras providências. Disponível em: <http://www.planalto.gov.br/ccivil 03/leis/19985.htm>. Acesso em 22/09/2014. 
. Decreto Federal no 6.040/2007 de 7 de fevereiro de 2007. Institui a Política Nacional de Desenvolvimento Sustentável dos Povos e Comunidades Tradicionais. Disponível em <http://www.planalto.gov.br/ccivil 03/ ato2007-2010/2007/decreto/d6040.htm> Acesso em 12/11/2014.

BROCKINGTON, D.; SCHMIDT-SOLTAU, K. The social and environmental impacts of wilderness and development. Oryx, v. 38, n.2, p 13, 2004.

BROCKINGTON, D.; IGOE, J.; SCHMIDT-SOLTAU, K. Conservation, human rights, and poverty reduction. Conservation Biology, v. 20, n.1, 250-252, 2006.

CABRAL, N. R. A. J. SOUZA. M. P. Área de Proteção Ambiental: planejamento e gestão de paisagens protegidas. São Carlos: Rima, 2005.

CAMEJO-RODRIGUES, J. C.; ASCENSÃO, L.; BONET A.; VALLÈS J. An ethnobotanical study of medicinal and aromatic plants in the Natural Park of "Serra de São Mamede" (Portugal). Journal of Ethnopharmacology. Copenhagen, Dinamarca. n. 89 v. 25, p. 199-209, 2003.

CHAZDON, R. L.; COE, F. G. Ethnobotany of woody species in second-growth, old-growth, and selectively logged forests of northeastern Costa Rica. Conservation biology, v. 13, n. 6, p. 1312-1322, 1999

COE, F. G. ANDERSON. G. J. Ethnobotany of the miskitu of eastern Nicaragua. Journal of Ethnobiology, n. 2, v. 17, p. $171-214,1997$.

DE POURCQ, K.; et al. Conflict in protected areas: Who says comanagement does not work? Plos One, v.10, n.12, 2015

DE POURCQ, K. et al. Understanding and Resolving Conflict Between Local Communities and Conservation Authorities in Colombia, World Development, 2017.

DIEGUES. A. C. O Mito Moderno da Natureza intocada. Hucitec. São Paulo, 2001.

DRUMMOND, G. M.; MARTINS, C. M.; ANGELO B. M. M.; SEBAIO, F. A.; ANTONINI, Y. Biodiversidade em Minas Gerais: um atlas para sua conservação. Fundação Biodiversitas, 2005.

DUDLEY, N.; ALI, N.; AND MACKINNON, K. Natural Solutions: Protected areas helping to meet the Sustainable Development Goals. Briefing, Gland, Switzerland, IUCN World Commission on Protected Areas, 2017.

FABRANDT. Zoneamento ecológico-econômico da área de proteção ambiental (APA) São José. Belo Horizonte: Fundação Alexander Brandt, 2000.

FERREIRA, L. C. Conflitos sociais e uso de recursos naturais: breves comentários sobre modelos teóricos e linhas de pesquisa. Política \& Sociedade. n. 7, p. 105-118, 2005.

FERREIRA, L. C. Conflitos sociais e uso de recursos naturais: breves comentários sobre modelos teóricos e linhas de pesquisa. Política \& Sociedade. n. 7, p. 105-118, 2005.

HANAZAKI, N. Comunidades, conservação e manejo: o papel do conhecimento ecológico local. Biotemas, v. 16, n. 1, p. 23-47, 2003.

IBGE- Instituto Brasileiro de Geografia e Estatística. Manuais técnicas em Geociências. 2a ed. Revista e ampliada, 2012.

LEUNG, Y. F.; SPENCELEY, A.; HVENEGAARD, G.; \& BUCKLEY, R. Tourism and visitor management in protected areas: Guidelines towards sustainability. Best Practice Protected Area Guidelines Series No. XX, Gland, Switzerland: IUCN, 2015.

MACEDO, S. R. Etnopesquisa crítica, etnopesquisa-formação. Brasília: Liber Livro Editora, 2006

MEDEIROS, R.; IRVING, M. A.; GARAY, I. Áreas protegidas no Brasil: interpretando o contexto histórico para pensar a inclusão social. In: IRVING, M. A. Áreas Protegidas e Inclusão Social: construindo novos significados. Rio de Janeiro, Aquários, p 15-38, 2006.

MESOUDI, A. Cultural Evolution: how Darwinian Theory Can Explain Human Culture and Synthesize the Social Sciences. Chicago: University of Chicago Press, p. 264, 2011. 
MINAS GERAIS. Decreto no. 30.934, de 16 de fevereiro de 1990. Declara como de proteção ambiental área de terreno situado na Serra São José, nos Municípios de Tiradentes, Prados, Coronel Xavier Chaves e São João Del Rei. Disponível em:< https://sogi8.sogi.com.br/Arquivo/Modulo113.MRID109/Registro26832/documento\%201.pdf >. Acesso em 22/09/2015.

MINAS GERAIS. Decreto no. 43.908, de 05 de novembro de 2004. Cria o Refúgio Estadual de Vida Silvestre Libélulas da Serra de São José nos Municípios de Tiradentes, Santa Cruz de Minas, São João Del Rei, Coronel Xavier Chaves e Prados. Disponível em: < http://www.sian.mg.gov.br/sla/download.pdf?idnorma2057 >. Acesso em 22/09/2015.

MINAS GERAIS. Secretaria de Estado de Meio Ambiente e desenvolvimento sustentável, Deliberação do Conselho Estadual de Política Ambiental no 367, de 15 de dezembro de 2008. Diário do executivo. Disponível em: < http://www.siam.mg.gov.br/sla/download.pdf?idNorma=9450 $>$. Acesso em: 15 de set. de 2016.

MMA-Ministério do Meio Ambiente. Convenção Sobre Diversidade Biológica, 2000 . Disponível em: <http://www.mma.gov.br/estruturas/sbf dpg/ arquivos/cdbport.pdf >. Acesso em 13/11/2014

e INSTITUTO CHICO MENDES DE CONSERVAÇÃO DA BIODIVERSIDADE. INSTRUÇÃO NORMATIVA № 26, DE 4 DE JULHO DE 2012 DOU de 06/07/2012 (no 130, Seção 1, pág. 84). Disponível em: < https://www.jusbrasil.com.br/diarios/38495887/dou-secao1-06-07-2012-pg-84 . Acesso em 30 de jun. 2018.

OLIVEIRA FILHO, A. T. et al. Definição e delimitação de domínios e subdomínios das paisagens naturais do estado de Minas Gerais. In SCOLFORO, J. R.; CARVALHO, L. M. T. (Ed.). Mapeamento e Inventário da Flora e dos Reflorestamentos de Minas Gerais. Lavras: UFLA 2006. cap. 1, p. 21-35.

OVETZ, R. The bottom line: an investigation of the economic, cultural and social costs of industrial longline fishing in the Pacific and the benefits of sustainable use marine protected areas. Mar Policy, v. 30, p. 809-820, 2006.

PÁDUA, M. T. J. Área de proteção ambiental. In: ÁVILA, A. P.; BENJAMIN, A. H. Direito ambiental das áreas protegidas: o regime jurídico das unidades de conservação. Rio de Janeiro: Forense Universitária, 2001.p. 425-433.

PITTOCK, J.; FINLAYSON, M.; ARTHINGTON, A. H.; ROUX, D.; MATTHEWS, J. H.; BIGGS, H.; \& HERMOSO, V. Managing freshwater, river, wetland and estuarine protected areas. Protected Area Governance and Management, p. 569-608, 2015.

SANTOS L. L., VIEIRA F. J., NASCIMENTO L. G. S., SILVA, A.C.O., SANTOS L. L., SOUSA, G. M. Techniques for Collecting and Processing Plant Material and Their Application in Ethnobotany Research: in ALBUQUERQUE U. P. et al. Methods and Techniques in Ethnobiology and Ethnoecology. Springer New York Heidelberg Dordrecht London, 2014

SCHERL, L. M. et al. As áreas protegidas podem contribuir para a redução da pobreza? Oportunidades e limitações. IUCN: Gland, Suíça e Cambridge, Reino Unido. 2006.

SIEBER, S. S., SILVA T. C., CAMPOS, L. Z. O. ZANK, S., ALBUQUERQUE, U. P. Participatory Methods in Ethnobiological and Ethnoecological Research: in ALBUQUERQUE U. P. et al. Methods and Techniques in Ethnobiology and Ethnoecology. Springer New York Heidelberg Dordrecht London, 2014

SILVA, T. C., CRUZ, M. P. ARAÚJO, T. A. S., SCHWARZ, M. L., ALBUQUERQUE, U.P. Methods in Research of Environmental Perception: in ALBUQUERQUE U. P. et al. Methods and Techniques in Ethnobiology and Ethnoecology. Springer New York Heidelberg Dordrecht London, 2014

SILVEIRA-JUNIOR, W. J.; SALVIO, G. M. M.; MOURA, A, S.; SOUZA, C. R.; FONTES, M. A. L. Payment for environmental services: alleviating the conflict of parks versus people. Journal of Tropical Forest Science, v. 32, n.1, p 8-16, 2020.

SIMMEL G. The Sociology of Conflict. American Journal of Sociology. Chicago: v. 9, n. 4, p. 490-525, 1986.

STOLTON, S.; DUDLEY, N.; AVCIOGLU ÇOKÇALIŞKAN, B., HUNTER, D., IVANIĆ, K. Z., KANGA, E., KETTUNEN, M., KUMAGAI, Y., MAXTED, N., SENIOR, J., WONG, M., KEENLEYSIDE, K., MULROONEY, D., WAITHAKA, J. Values and benefits of protected areas, in. LOCKWOOD M., A. KOTHARI, S. FEARY and I. Pulsford (eds) Protected Area Governance and Management, ANU Press, Canberra, Australia, p. 145$168,2015$. 
TOLEDO, V. M. ORTIZ-ESPEJEL, B., CORTÉS L., MOGUEL P, ORDOÑEZ M. J.The Multiple Use of Tropical Forests by Indigenous Peoples in Mexico: a Case of Adaptive Management. Conservation Ecology n.7, v. 3, 2003

VAYRYNEN, R. (Ed.). New directions in conflict theory: conflict resolution and conflict transformation. London: Newbury Park Sage, 1991.

VEDELD, P.; JUMANE, A.; WAPALILA, G.; \& SONGORWA, A. Protected areas, poverty and conflicts: A livelihood case study of Mikumi National Park, Tanzania. Forest Policy and Economics, v. 21, p. 20-31, 2012.

YOUNG, J. C., MARZANO, M., WHITE, R. M., MCCRACKEN, D. I., REDPATH, S. M., CARSS, D. N., QUINE C. P.; \& WATT, A. D. The emergence of biodiversity conflicts from biodiversity impacts: characteristics and management strategies. Biodiversity and Conservation, v. 19, n.14, p. 3973-3990, 2010.

YOUNG, J. C., SEARLE, K., BUTLER, A., SIMMONS, P., WATT, A. D., \& JORDAN, A. The role of trust in the resolution of conservation conflicts. Biological Conservation, v. 195, p. 196-202, 2016 